\title{
Risk stratification after acute myocardial infarction by Doppler stroke distance measurement
}

\author{
R J Trent, J M Rawles
}

\begin{abstract}
Objective-To establish the value of Doppler stroke distance measurement as a predictor of mortality risk following acute myocardial infarction.

Design- Follow up study.

Setting-Coronary care unit of a teaching and district general hospital.
\end{abstract}

Subjects-378 patients (mean age 61 years) with acute myocardial infarction followed up for a mean of five years (range 2-7 years); 299 (79\%) patients received thrombolysis.

Main outcome measures-Stroke distance (the systolic velocity integral of blood flow in the aortic arch (percentage of age predicted normal value)); presence or absence of left ventricular failure on the admission chest radiograph; the codified admission ECG; death during follow up.

Results-Mean (SD) stroke distance was $81(19) \%$ and five year survival $76 \%$. For patients with stroke distance $>100 \%$ $(\mathrm{n}=60), \quad 82-100 \% \quad(\mathrm{n}=134), \quad 63-81 \%$ $(n=122)$, and $<63 \%(n=62)$, the one month mortality rates were $0 \%, 1.5 \%, 4 \%$, and $18 \%$, respectively; the corresponding estimates for mortality at five years were $17 \%, 19 \%, 24 \%$, and $43 \%$. Survival was independently related to age $(p<0.0001)$, stroke distance $(p<0.0001)$, and chest radiograph appearance $(p=0.002)$, but not to ECG codes $(p=0.31)$ or receipt of thrombolysis $(p=0.60)$. The areas under receiver operator characteristic plots for stroke distance measurements were $82 \%$, $76 \%, 71 \%$, and $65 \%$ for deaths within one month, six months, one year, and two years, respectively.

Conclusions-The bedside measurement of stroke distance stratifies mortality risk after acute myocardial infarction. The predictive ability of this simple measure of left ventricular systolic function compares well with published accounts of the more complex measurement of ejection fraction.

(Heart 1999;82:187-191)

Keywords: stroke distance; Doppler; myocardial infarction; mortality risk; risk stratification

Left ventricular function is a prime determinant of survival after acute myocardial infarction. ${ }^{1-6}$ Left ventricular function should be measured in all infarct patients for optimal management. In most published series, and in clinical practice, left ventricular function is measured and expressed as its ejection fraction. Of the available methods of measurement, only echocardiography (using the modified Simpson's rule method) is practicable at the bedside, but there are inherent methodological difficulties, and agreement with radionuclide ventriculography is not good. ${ }^{7}$ The use of semiquantitative observer analysis ${ }^{9}$ or visual estimation $^{810}$ are alternative approaches. Although echocardiography might seem to be an ideal tool with which to make repeated measurements in acutely ill patients, some patients are "non-echogenic",5811 12 and a skilled echocardiographer is required. ${ }^{9}$

Left ventricular function can also be assessed by determination of stroke distance, the systolic velocity integral of blood flow, sampled in the aortic arch. This can be measured at the bedside with simple non-imaging Doppler equipment in over $90 \%$ of subjects with acute myocardial infarction. ${ }^{13}$ Reliable measurements can be made by technical, medical or nursing staff after only a short period of training. Because of its ease of measurement, stroke distance has potential advantages as a means of stratifying mortality risk after acute myocardial infarction, particularly in hospitals with limited facilities. We report the follow up of patients with acute myocardial infarction, relating mortality to measurements of stroke distance and clinical findings made during the initial hospital admission.

\section{Patients and methods}

We have previously reported three series of patients with suspected acute myocardial infarction in whom stroke distance has been measured. ${ }^{13-15}$ The present study is a follow up of the 378 of these patients who had a diagnosis at discharge or death of acute myocardial infarction, defined as the presence of two or more of the following: more than 30 minutes of characteristic chest pain, new $Q$ waves on the ECG, and a rise of cardiac enzymes to at least twice the upper limit of normal.

In all patients stroke distance was measured within 48 hours of admission, and then daily for 10 days or until discharge or death, whichever was the earlier. Stroke distance was measured by a technician using a Doptek Spectrum Analyser (Deltex Medical Ltd, Chichester, West Sussex, UK) with a $2 \mathrm{MHz}$ continuous wave ultrasound probe directed at the aortic arch through the suprasternal window. Mean stroke distance was averaged from as many beats as were stored in a $10 \mathrm{sec}-$ ond sequence, evaluated by on screen planimetry. The reproducibility of this technique in our hands is $9 \% .{ }^{16}$ In this paper, stroke distance refers to the last recorded measurement before death or discharge, and the results are
Accepted for publication 13 March 1999 
expressed as percentages of age predicted normal values. ${ }^{17}$

The ECG recorded on admission was coded according to the schema used by the international study of infarct survival group, ${ }^{18}$ and shown in table 1 . The admission chest radiograph was coded from the radiologist's report according to the schema of Gottlieb and colleagues $^{19}$ (table 2). Follow up of study patients was from hospital records and the Scottish registry office.

STATISTICAL METHODS

The relations between survival, stroke distance, and other factors were computed with the statistical package for the social sciences. Multivariate logistic regression was used to examine short term survival ( $\leqslant 2$ years, uncensored), and Cox's proportional hazards model for survival in the long term. In order to compare the short term prognostic ability of stroke distance with published studies of left ventricular ejection fraction, the areas under receiver operator characteristic (ROC) plots were determined for prediction of death by one month, six months, one and two years; SEs of these areas were calculated by the method of Hanley and $\mathrm{McNeill.}{ }^{20}$ Significance was taken as $\mathrm{p}<0.05$.

\section{Results}

The mean (SD) age of 378 patients in this study was 61 (9.9) years; $299(79 \%)$ received thrombolytic treatment. Follow up was for a mean of five years (1813 days) with a range of 2-7 years (758-2686 days). The numbers of deaths by one month, one year, and two years were $18(5 \%), 41(11 \%)$, and $57(15 \%)$, respectively. Beyond two years follow up, actuarial survival was calculated by the method of Kaplan-Meier, and mortality at five years was estimated as $24 \%$.

Mean (SD) stroke distance was 81 (19)\% with a normal distribution. For patients with stroke distance $>100 \%$ (mean $+>1 S D$;

Table 1 Number of patients with various abnormalities on the admission ECG

\begin{tabular}{|c|c|c|c|c|}
\hline ECG appearance & Code & Number & $\begin{array}{l}\text { Died } \leqslant 1 \text { month } \\
(\text { mortality \%) }\end{array}$ & $\begin{array}{l}\text { Died } \leqslant 2 \text { years } \\
\text { (mortality \%) }\end{array}$ \\
\hline Not available & 0 & 6 & $1(17)$ & $3(50)$ \\
\hline Bundle branch block & 1 & 18 & $0(0)$ & $5(3)$ \\
\hline${ }^{\star}$ ST elevation: anterior alone & 2 & 98 & $10(10)$ & $18(18)$ \\
\hline${ }^{\star} \mathrm{ST}$ elevation: inferior alone & 3 & 99 & $3(3)$ & $10(10)$ \\
\hline${ }^{\star} \mathrm{ST}$ elevation: anterior and inferior & 4 & 20 & $1(5)$ & $2(10)$ \\
\hline ST elevation: other ST elevation & 5 & 27 & $0(0)$ & $3(11)$ \\
\hline ST depression, without ST elevation & 6 & 46 & $0(0)$ & $9(20)$ \\
\hline Q waves & 7 & 8 & $1(13)$ & $2(25)$ \\
\hline $\mathrm{T}$ wave inversion & 8 & 17 & $2(12)$ & $3(18)$ \\
\hline Normal & 9 & 17 & $0(0)$ & $2(12)$ \\
\hline Other abnormality & 10 & 22 & $0(0)$ & $0(0)$ \\
\hline Totals & & 378 & $18(5)$ & $57(15)$ \\
\hline
\end{tabular}

* ST elevation $\geqslant 1 \mathrm{~mm}$ in two adjacent limb leads or $\geqslant 2 \mathrm{~mm}$ in two adjacent precordial leads.

Table 2 Number of patients with various abnormalities on the admission chest radiograph

\begin{tabular}{llccc}
\hline Chest radiograph appearance & Code & Number & $\begin{array}{l}\text { Died } \leqslant 1 \text { month } \\
\text { (mortality \%) }\end{array}$ & $\begin{array}{l}\text { Died } \leqslant 2 \text { years } \\
\text { (mortality\%) }\end{array}$ \\
\hline Not available & 0 & 51 & $5(10)$ & $14(27)$ \\
Normal & 1 & 234 & $5(2)$ & $20(9)$ \\
Pulmonary venous congestion & 2 & 23 & $3(13)$ & $4(17)$ \\
Interstitial oedema & 3 & 51 & $1(2)$ & $11(22)$ \\
Alveolar oedema & 4 & 19 & $4(21)$ & $8(42)$ \\
Totals & & 378 & $18(5)$ & $57(15)$ \\
\hline
\end{tabular}

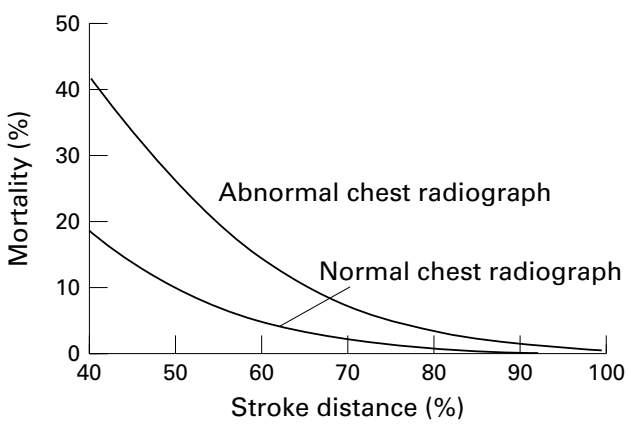

Figure 1 Graphs of logistic regression equation relating probability of death within one month to stroke distance, with and without a normal chest radiograph.

$\mathrm{n}=60), 82-100 \%($ mean $+\leqslant 1 S D ; \mathrm{n}=134)$, $63-81 \%$ (mean $-<1 S D ; n=122$ ), and $<63 \%$ (mean $-\geqslant 1 S D ; n=62$ ), the one month mortality rates were $0 \%, 1.5 \%, 4 \%$, and $18 \%$, respectively; the corresponding estimates for mortality at five years were $17 \%, 19 \%, 24 \%$, and $43 \%$. The number of subjects and mortality rates of patients with various appearances of the admission ECG and chest radiograph are given in tables 1 and 2 .

\section{MORTALITY WITHIN ONE MONTH}

By multivariate logistic regression analysis, stroke distance $(p<0.0001)$ and the chest radiograph code $(p=0.02)$ were independently related to mortality within one month; age $(p=0.26)$, ECG code $(p=0.34)$, and receipt of thrombolytic treatment $(p=0.68)$ were not related to early mortality. Figure 1 shows a plot of the logistic regression equation relating stroke distance to the probability of death within one month; the model has been simplified by categorising the chest radiograph as normal or abnormal. The risk of death within one month varies more than 10-fold and is steeply related to stroke distance measurements below $100 \%$. For any value of stroke distance the risk of death is more than doubled by the lack of a normal chest radiograph.

LONG TERM SURVIVAL UP TO SEVEN YEARS Survival up to seven years was independently related to age $(p<0.0001)$, stroke distance $(p<0.0001)$, and the chest radiograph code $(p=0.002)$; neither the ECG $(p=0.31)$ nor receipt of thrombolytic treatment $(p=0.60)$ significantly influenced long term survival. Figure 2 shows Kaplan-Meier survival curves up to five years for all patients, and for those with stroke distance > 1SD above and below the mean for the study population. Figure 3 similarly shows survival for those with or without a normal chest radiograph.

ROC PLOTS

Figure 4 shows ROC plots for stroke distance and death at various times after entry to the study. These graphs illustrate the trade off between the sensitivity and the specificity of the prediction of death for different cut off values of stroke distance. The area under a curve indicates the overall predictive ability of the measure. The area under the curve of an ideal measure would be $100 \%$, while that of a com- 


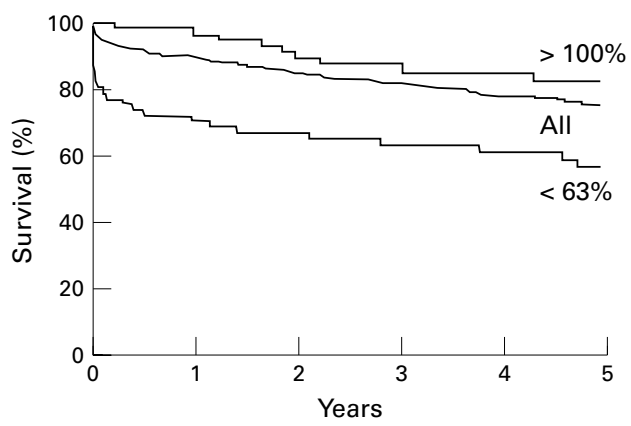

Figure 2 Survival curves for all patients (mean stroke distance $81 \%$ ), and for those with stroke distance $>100 \%$ and $<63 \%$.

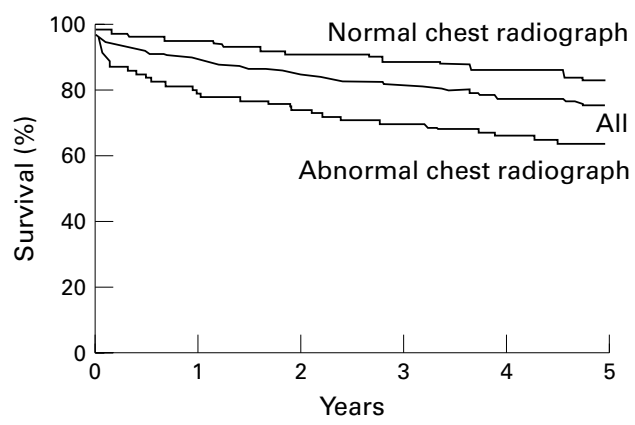

Figure 3 Survival curves for all patients, and for those with or without a normal chest radiograph on admission.

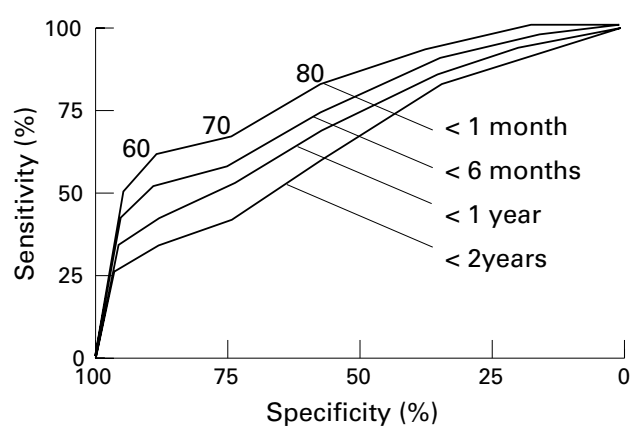

Figure 4 ROC curves for the prediction of death within one month, six months, one year, and two years for various values of stroke distance. Inflections of the curves for stroke distances of $60 \%, 70 \%$, and $80 \%$ are indicated.

pletely non-predictive test would be $50 \%$. The areas (SE) under ROC plots for stroke distance measurements were $82(5.4) \%, 76(4.9) \%, 71$ (4.6)\%, and 65 (4.2)\% for deaths within one month, six months, one year, and two years, respectively. In each case the lower 95\% confidence interval for the area under the curve exceeds $50 \%$, indicating that prediction of death is significantly better than chance.

Table 3 Prediction of death up to one year after myocardial infarction by different methods of measuring left ventricular function

\begin{tabular}{lllll}
\hline Author & Method & Duration & AUC (\%) & $95 \%$ CI (2SE) \\
\hline${ }^{\star}$ Multicenter group & & & \\
Fioretti $e t a l^{2}$ & RN EF & $<1$ year & 75 & 67.7 to 82.1 \\
Nicod $e t a l^{4}$ & RN EF & $<1$ year & 74 & 65.6 to 82.0 \\
Volpi $e t a \bar{l}^{\text {Zaret } e t a l^{6}}$ & RN/Angio EF & $<1$ year & 69 & 63.6 to 74.4 \\
Trent $e t a l^{13}$ & Echo EF & $<6$ months & 75 & 69.6 to 80.4 \\
& RN EF & $<1$ year & 67 & 59.4 to 75.4 \\
& Doppler Sdist & $<6$ months & 76 & 66.2 to 85.8 \\
& & $<1$ year & 71 & 61.8 to 80.2 \\
\hline
\end{tabular}

*Multicenter Postinfarction Research Group.

Angio, cineangiography; RN, radionuclide ventriculography; EF, ejection fraction; Echo, echocardiography; Sdist, stroke distance; AUC, area under curve; CI, confidence intervals.
Prediction is better for earlier than for later deaths.

\section{Discussion}

In this study we have shown that after acute myocardial infarction, stroke distance provides prognostic information additional to that from knowledge of the patient's age, ECG, chest radiograph, and reperfusion treatment. A stroke distance measurement $>100 \%$ was associated with zero mortality at one month, and a stroke distance measurement $<63 \%$ was associated with $18 \%$ and $43 \%$ mortality at one month and five years, respectively. Stroke distance is measured simply at the bedside by a technician, with relatively cheap equipment and negligible running costs. The measurement is non-invasive, well tolerated, and without the risks of ionising radiation.

A limitation of the study is that the stroke distance measurement used for prognostication was the last one available before death or discharge, not one recorded at a fixed interval after infarction. Stroke distance is generally lower on admission than at discharge, and patients dying within 10 days of admission may not have had time to normalise stroke distance, introducing a bias in favour of the measurement. We believe the bias to be trivial, however, because the first available stroke distance measurement has a similar prognostic power to the last. The last available stroke distance was used in this study because its timing shortly before discharge would be closest to that of ejection fraction with which it is being compared.

COMPARISON OF STROKE DISTANCE AND EJECTION FRACTION

In this study, left ventricular ejection fraction was not measured in most patients, so direct comparison with stroke distance is not possible. There are many studies, however, that relate survival after acute myocardial infarction to left ventricular ejection fraction, and several of them contain sufficient data to enable the areas under ROC plots to be calculated. The area under an ROC plot summarises the measure's prognostic efficiency, allowing comparisons between left ventricular ejection fraction and stroke distance. The various studies are summarised in table 3.

The areas under ROC plots for six month and one year mortality after acute myocardial infarction are similar for stroke distance and ejection fraction, and also for acute radiographic and clinical evidence of left ventricular failure. Volpi and colleagues demonstrated an area under an ROC plot of $75 \%$ for prediction of death at six months after myocardial infarction, compared with $76 \%$ for stroke distance at the same time. ${ }^{5}$ Similarly, the area under the ROC from Nicod and colleagues for prediction of cardiac death at one year was $69 \%$ when heart failure diagnosed at time of admission was included as a variable. ${ }^{4}$ Data from the multicentre group, ${ }^{1}$ and Fioretti and colleagues $^{2}$ yielded ROC areas of $75 \%$ and $74 \%$, respectively, for cardiac deaths at one year, compared with our value of $71 \%$ for all 
cause mortality predicted from stroke distance measurements. The $95 \%$ confidence intervals for the areas under ROC plots in all these studies show considerable overlap.

In this study, patients with a stroke distance at discharge $>100 \%$ of the age predicted normal value had one month and one year mortality rates of $0 \%$ and $3 \%$, respectively, similar to those reported by Nicod and colleagues $^{4}$ in postinfarct patients with no clinical evidence of heart failure during hospital admission and a normal radionuclide ejection fraction at discharge. In the thrombolytic era, Volpi and colleagues ${ }^{5}$ reported six month mortality of $1.1 \%$ in subjects with an ejection fraction of $\geqslant 60 \%$, and $1.5 \%$ for those with ejection fraction $>40 \%$, while Schreiber and colleagues ${ }^{21}$ described one and 12 month mortality of $0.6 \%$ and $3.9 \%$ in patients with one or two vessel coronary disease and good left ventricular function assessed by radionuclide ventriculography. Neither exercise testing nor perfusion scintigraphy were routinely performed before discharge in our series, and any additional improvement of risk prediction by these investigations cannot be assessed. However, our results suggest that patients with a stroke distance $>100 \%$ would be suitable for early discharge and subsequent outpatient management.

A converse situation was found in those patients with depressed stroke distance. The one month mortality for those patients with a predischarge value $<63 \%$, more than 2 SDs below normal, and more than 1SD below the mean value for infarct patients in the study, was $18 \%$, with one and five year rates of $29 \%$ and $43 \%$, respectively. These patients are likely to benefit from aggressive management, including early angiography with a view to revascularisation. $^{22}$

STROKE DISTANCE AND CHEST RADIOGRAPHY Stroke distance and chest radiography were independent predictors of early and long term survival. The combination of predischarge stroke distance with the admission chest radiograph was better than either alone in predicting mortality. Mortality within one month varied from $0-18 \%$ between those with the highest and lowest stroke distance at discharge, regardless of radiographic findings at presentation, while for any value of stroke distance, mortality was more than doubled by the lack of a normal chest radiograph. In the prethrombolytic era a similar prognostic synergy was shown after myocardial infarction for the combination of predischarge ejection fraction and clinical and/or radiographic evidence of left ventricular failure on admission. ${ }^{419}$ This is likely to be a manifestation of the differing aetiologies of radiographic and Doppler abnormalities performed at different times during the hospital admission. Depressed stroke distance or ejection fraction reflect systolic dysfunction, whereas pulmonary congestion is more likely to reflect diastolic dysfunction, ${ }^{23}{ }^{24}$ with or without mitral incompetence. ${ }^{25}$ Diastolic function is influenced by factors other than infarction, particularly the presence of ischaemia. ${ }^{24}{ }^{26}{ }^{27}$ Moreover, the admission chest radiograph reflects acute, postischaemic "stunned" left ventricular function, with potential for recovery, ${ }^{28-30}$ whereas predischarge stroke distance reflects residual left ventricular function after thrombolytic treatment. Our data suggest that the admission chest radiograph remains an important independent prognostic index even in the thrombolytic era.

\section{CONCLUSIONS}

The measurement of stroke distance at the bedside of the patient with acute myocardial infarction is capable of differentiating high and low risk individuals with a predictive accuracy similar to that published for left ventricular ejection fraction. The prognostic information obtained by this method is synergistic with radiographic evidence of left ventricular failure. The measurement itself is relatively easy to perform, and can be obtained in a high percentage of subjects. It is non-invasive, innocuous, inexpensive, and requires minimal operator training. This method offers the potential for early risk stratification of patients with myocardial infarction, improving the identification of those who may need early intervention, or conversely, those who are at low risk and do not require high dependency care.

1 Multicentre Post Infarction Research Group. Risk stratification and survival after myocardial infarction. $N \mathrm{Engl} f \mathrm{Med}$ tion and survival af

2 Fioretti P, Brower RW, Simoons ML, et al. Relative value of clinical variables, bicycle ergometry, rest radionuclide ventriculography and 24 hour ambulatory electrocardiographic monitoring at discharge to predict 1 year survival fter myocardial infarction. $\mathcal{F}$ Am Coll Cardiol 1986;8:40-9.

3 White HD, Norris RM, Brown MA, et al . Left ventricular end-systolic volume as the major determinant of survival after recovery from myocardial infarction. Circulation 1987; 76:44-51.

4 Nicod P, Gilpin E, Dittrich H, et al. Influence on prognosis and morbidity of left ventricular ejection fraction with and without signs of left ventricular failure after acute myocardial infarction. Am $\mathcal{F}$ Cardiol 1988;61:1165-71.

5 Volpi A, De Vita C, Franzosi MG, et al. Determinants of 6 -month mortality in survivors of myocardial infarction after thrombolysis: results of the GISSI-2 data base. Circuafter thrombolysis: resuls
lation 1993;88:146-9.

6 Zaret BL, Wackers FJ, Terrin ML, et al. Value of radionuclide rest and exercise left ventricular ejection fraction in assessing survival of patients after thrombolytic therapy for acute myocardial infarction: results of thrombolysis in myocardial infarction (TIMI) phase II study. $\mathcal{F}$ Am Coll Cardiol 1995;26:73-9.

7 Albin G, Rahko PS. Comparison of echocardiographic quantification of left ventricular ejection fraction to radionuclide angiography in patients with regional wall motion abnormalities. Am F Cardiol 1990;65:1031-2.

8 Jensen-Urstad K, Bouvier F, Hojer J, et al. Comparison of different echocardiographic methods with radionuclide maging for measuring left ventricular ejection fraction during acute myocardial infarction treated by thrombolytic therapy. Am f Cardiol 1998;81;538-44.

9 Kober L, Torp-Pedersen C, Carlsen J, et al. An echocardiographic method for selecting high risk patients shortly after acute myocardial infarction, for inclusion in multi-centre acute myocardial infarction, for inclusion in multi-centre
studies (as used in the TRACE study). Eur Heart $f$ 1994;15:1616-20.

10 Stamm RB, Carabello BA, Mayers DL, et al. Twodimensional echocardiographic measurement of left ventricular ejection fraction: prospective analysis of wht constitutes an adequate examination. Am Heart $\mathcal{F}$ 1982; 104: $136-44$

11 Savage DD, Garrison RJ, Kannel WB, et al. Considerations in the use of echocardiography in epidemiology: the Framngham study. Hypertension 1987;9:40-4

12 St John Sutton M, Pfeffer M, Plappert T, et al. Quantitative two-dimensional echocardiographic measurements are major predictors of adverse cardiovascular events after acute myocardial infarction: the protective effects of captopril. Circulation 1994; 89:68-75.

13 Trent RJ, Rose EL, Adams JN, et al. Delay between the onset of symptoms of acute myocardial infarction and seeking medical assistance is influenced by left ventricular function.

14 Metcalfe MJ, Rawles JM. Stroke distance in acute myocardial infarction: a simple measurement of left ventricular function. Lancet 1989;i:1371-3. 
15 Grampian Region Early Anistreplase Trial Group. Feasibility, safety, and efficacy of domiciliary thrombolysis by gen-

16 Mayo A, Rawles JM. Comparison of four different Doppler instruments used to measure linear and volumetric cardiac output: a study of reproducibility and agreement. Ultrasound Med Biol 1991;17:347-53

17 Haites NE, McLennan F, Mowat DHR, et al. Assessment of cardiac output by the Doppler ultrasound technique alone. Br Heart f 1985;53:123-9.

18 Second International Study of Infarct Survival Collaborative Group. Randomised trial of intravenous streptokinase, oral aspirin, both, or neither among 17187 cases of suspected acute myocardial infarction: ISIS-2, Lancet 1988;ii:349-60.

19 Gottlieb SS, Moss AJ, McDermott M, Eberly S. Interrelation of left ventricular ejection fraction, pulmonary congestion and outcome in acute myocardial infarction. $A m \mathcal{F}$ tion and outcome in acute
Cardiol 1992;69:977-84.

20 Hanley JA, McNeill BJ. The meaning and use of the area under a receiver operating characteristic (ROC) curve. under a receiver operating
Radiology 1982;143;29-36.

21 Schreiber T, Marsalese D, Griffin J, et al. Identification of ultra-low risk patients following primary angioplasty fo acute myocardial infarction [abstract]. $\mathcal{F} \mathrm{Am}$ Coll Cardiol 1996;27:83A

22 Peterson ED, Shaw CJ, Califf RM. Risk stratification after myocardial infarction. Ann Intern Med 1997;126:561-82.
23 Noble RJ. Myocardial infarction with hypotension. Chest 1991;99:1012

24 Grossman W. Diastolic dysfunction and congestive heart failure. Circulation 1990;81(suppl III): 1-7.

25 Clancy KF, Hakki AH, Iskandrian AS, et al. Forward ejection fraction: a new index of left ventricular ejection fraction in mitral regurgitation. Am Heart f 1985;110:65864

26 Dwyer EM Jr, Greenberg HM, Steinberg G, and the Multicenter Post-Infarction Research Group. Clinical characteristics and natural history of survivors of pulmonary congestion during myocardial infarction. Am f Cardiol 1989;63: 1423-8.

27 Aroesty JM, McKay RG, Heller GV, et al. Simultaneous assessment of left ventricular systolic and diastolic function during pacing-induced ischaemia. Circulation 1985;71: during pacin 800 .

28 Braunwald E, Kloner RA. The stunned myocardium: prolonged, post ischaemic ventricular dysfunction. Circulaprolonged, post isch

29 Ito H, Tomooka T, Sakai N, et al. Time course of functional improvement in stunned myocardium in risk area in patients with reperfused anterior infarction. Circulation

1993;87:355-62.
30 Pfisterer ME, Buser P, Osswald S, et al . Time dependence of left ventricular recovery after delayed recanalisation of an occluded infarct-related coronary artery: findings of a pilot study. $\mathcal{F}$ Am Coll Cardiol 1998;32:97-102. 